\title{
Tails of animism: a joint burial of humans and foxes in Pre-Pottery Neolithic Motza, Israel
}

Hagar Reshef ${ }^{1,}$, Marie Anton $^{2,3}$, Fanny Bocquentin $^{4}$, Jacob Vardi $^{5}$,
Hamoudi Khalaily $^{6}$, Lauren Davis
, Guy Bar-Oz

The recent discovery of a Late/Final Pre-Pottery Neolithic B burial of an adult and two children associated with fox bones at the site of Motza, Israel, demonstrates the broader socio-cultural perspective, and possibly continued animistic world views, of Neolithic foragers at the onset of the agricultural revolution.

Keywords: Israel, Neolithisation, burial, animism, small carnivores, fox

Recent excavations at the Pre-Pottery Neolithic B mega-site of Motza (7600-6000 BC), central Israel, have revealed a rare human burial with two foxes. The fox bones were dismembered, except for one foot found in articulation, and scattered among the human remains. What could this burial reveal about interactions between humans and small carnivores in the eighth and seventh millennia BC? We propose that Neolithisation entails closer relations between humans and small carnivores, relations that find expression in ritual practice. This is an animistic reflection of an anthropogenic ecology, which is advantageous to such animals and can be related to the general transition to agriculture in the Levant during this period.

Motza, located in the Judean Hills west of Jerusalem, is one of the largest sites in the southern Levant, approximately 40ha (Figure 1). It was previously excavated (Khalaily et al. 2007) and is remarkable for its architecture, plaster floors, a lithic assemblage rich in arrowheads, multiple graves and numerous animal bones. As one of the earliest and largest agricultural villages in the Mediterranean phytogeographic zone, Motza has much to

1 Department of Archaeology, University of Haifa, Multi-Purpose Building, Abba Khoushy Avenue 199, Haifa 3498838, Israel

2 École Doctorale d'Archéologie, Université Paris 1, Panthéon-Sorbonne, Paris, France

3 Musée de l'Homme, Éco-Anthropologie et Ethnologie, CNRS, UMR 7206, Paris, France

4 Maison de l'Archéologie et de l'Ethnologie, Équipe Ethnologie Préhistorique, CNRS, UMR 7041, Nanterre Cedex, France

5 Israel Antiquities Authority, Prehistoric Division, Har Hotzvim, Ha-Marpeh Street 5, Jerusalem, Israel

6 Israel Antiquities Authority, Prehistoric Archaeology, Rockefeller Museum, Sultan Suliman Street 27, Jerusalem, Israel

7 Zinman Institute of Archaeology, University of Haifa, Multi-Purpose Building, Abba Khoushy Avenue 199, Haifa 3498838, Israel

8 Recanati Institute for Maritime Studies, University of Haifa, Multi-Purpose Building, Abba Khoushy Avenue 199, Haifa 3498838, Israel

* Author for correspondence (Email: hagareshef@gmail.com) 
Hagar Reshef et al.

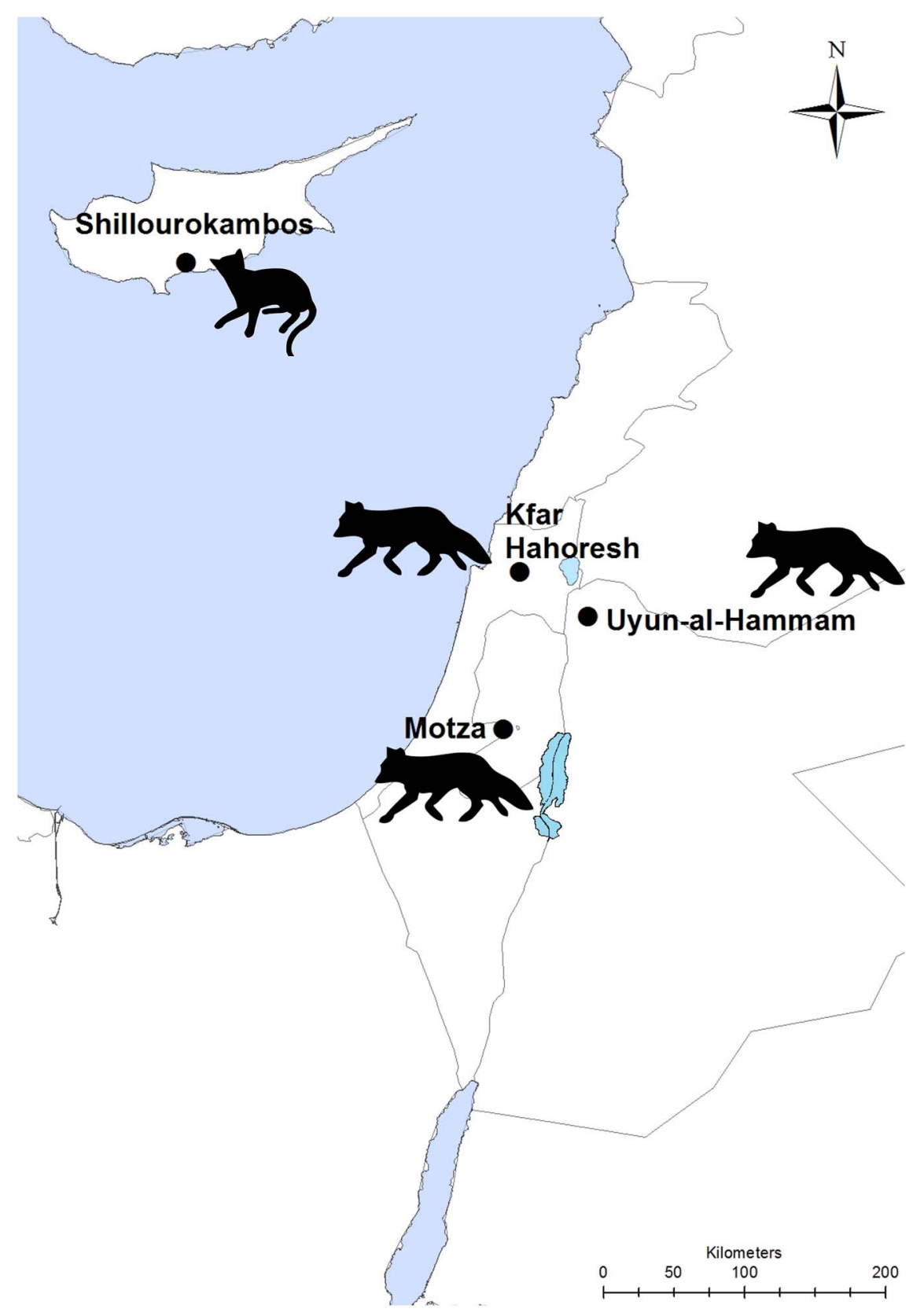

Figure 1. Map showing sites mentioned in the text. Base map: Flanders Marine Institute (2019) (available at: www. marineregions.org) (CC-licence).

(C) Antiquity Publications Ltd, 2019 


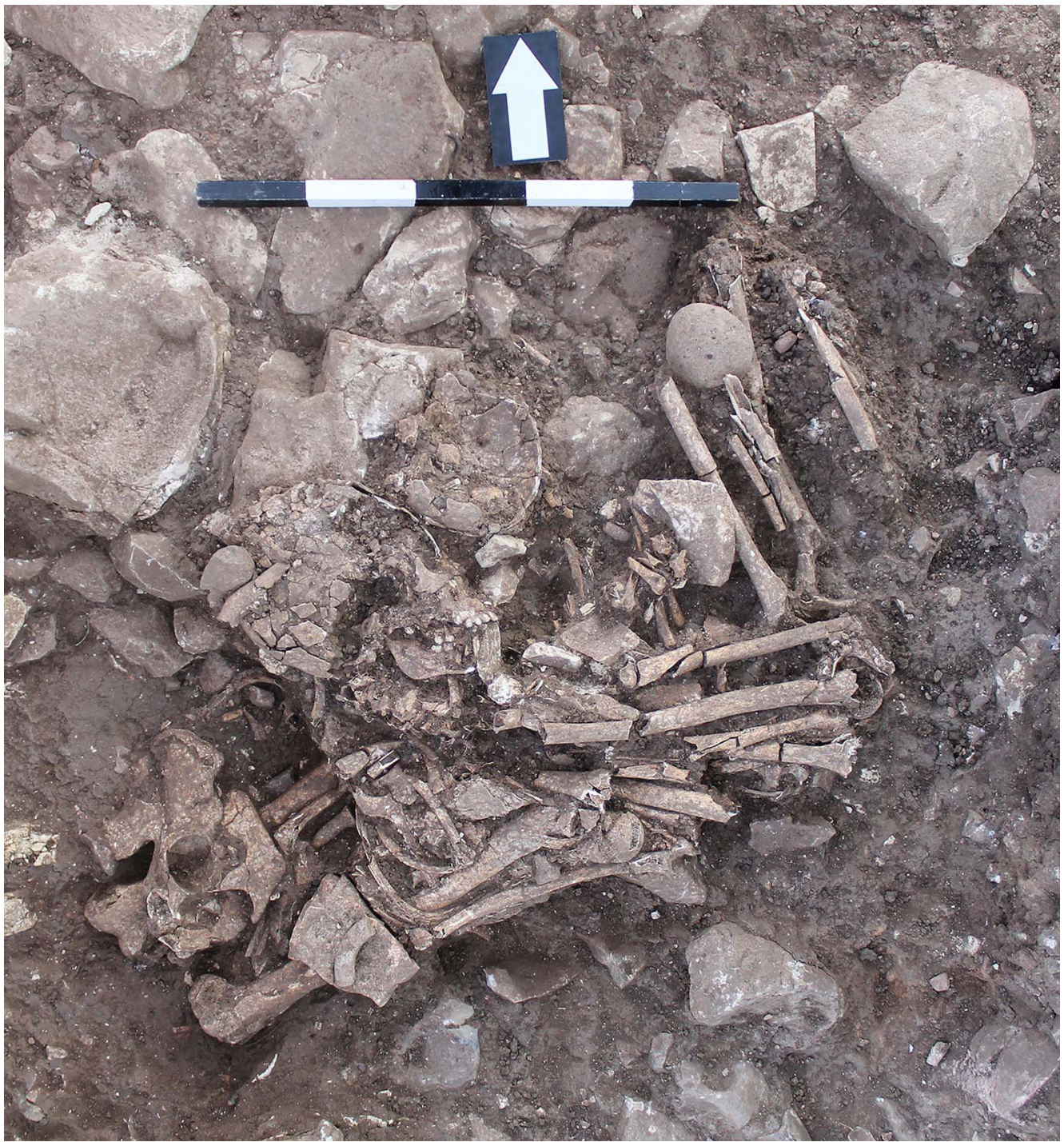

Figure 2. Photograph of the burial, courtesy of Lauren Davis, Israel Antiquities Authority.

contribute to our understanding of the transition from hunting and gathering to agriculture, and its economic, ecological, and social implications. We focus on a double burial of an adolescent and an adult with dismembered fox carcasses; we argue that this is important evidence of symbolism in the Neolithic and how it is reflected in the human-modified environments of the period.

Human burials with small carnivores (excluding domestic dogs) are known from a few sites (Davis \& Valla 1978; Tchernov \& Valla 1997) (Figure 1). At the pre-Natufian site (15 250-12 200 cal BC) of Uyun-al-Hammam, Jordan, a partly articulated fox skeleton was found in a human burial (Maher et al. 2011; Goring-Morris \& Belfer-Cohen 2013). Fox teeth and mandibles are often found in Natufian burials (Davis \& Valla 1978; Tchernov 


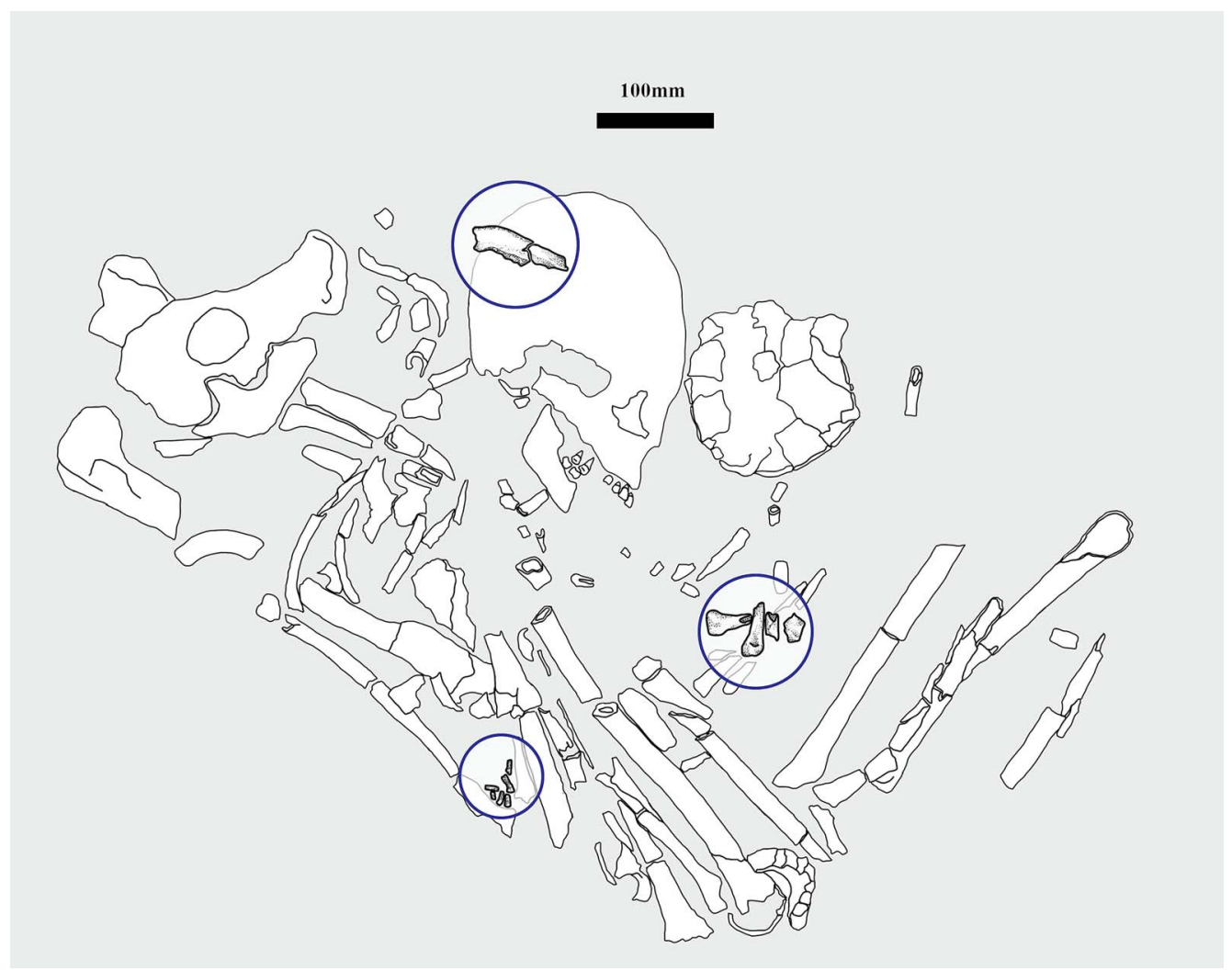

Figure 3. Illustration of the burial with fox elements outlined in blue. Drawing by Aya Marck.

\& Valla 1997; Goring-Morris 2005; Goring-Morris \& Belfer-Cohen 2013). At the Pre-Pottery Neolithic site of Shillourokambos, Cyprus (7500-7200 cal BC), an articulated cat skeleton was discovered in a human burial (Vigne et al. 2004; Le Mort et al. 2008). During the Neolithic, fox bones associated with human burials are known from the nearby Early Pre-Pottery Neolithic B site of Motza, where the burial of an adolescent associated with a fox mandible was excavated (H. Khalaily pers. comm.). At the Pre-Pottery Neolithic B ritual site of Kfar Hahoresh, human skulls were found with numerous fox mandibles, and partly articulated fox bones were excavated from two child burials (Horwitz \& Goring-Morris 2004; Goring-Morris 2005; Meier et al. 2017). Small carnivores, especially foxes, are associated with human burials before the Neolithic, and seem to have been symbolic.

The recently discovered Motza burial (Figures 2-3), found in area B at the site (Figure 4), is close to a wall and remnants of a plaster floor, suggesting a domestic context. The earliest burial in the pit is that of a child; it seems to have been disturbed by the double inhumation of an adult male (over 60 years old) and an unsexed adolescent. The adult skeleton was disarticulated and appears to have been interred in a rectangular container, which has not survived. This may indicate reburial at the same time as the adolescent, who was interred above the adult, lying on his right side in a flexed position. 


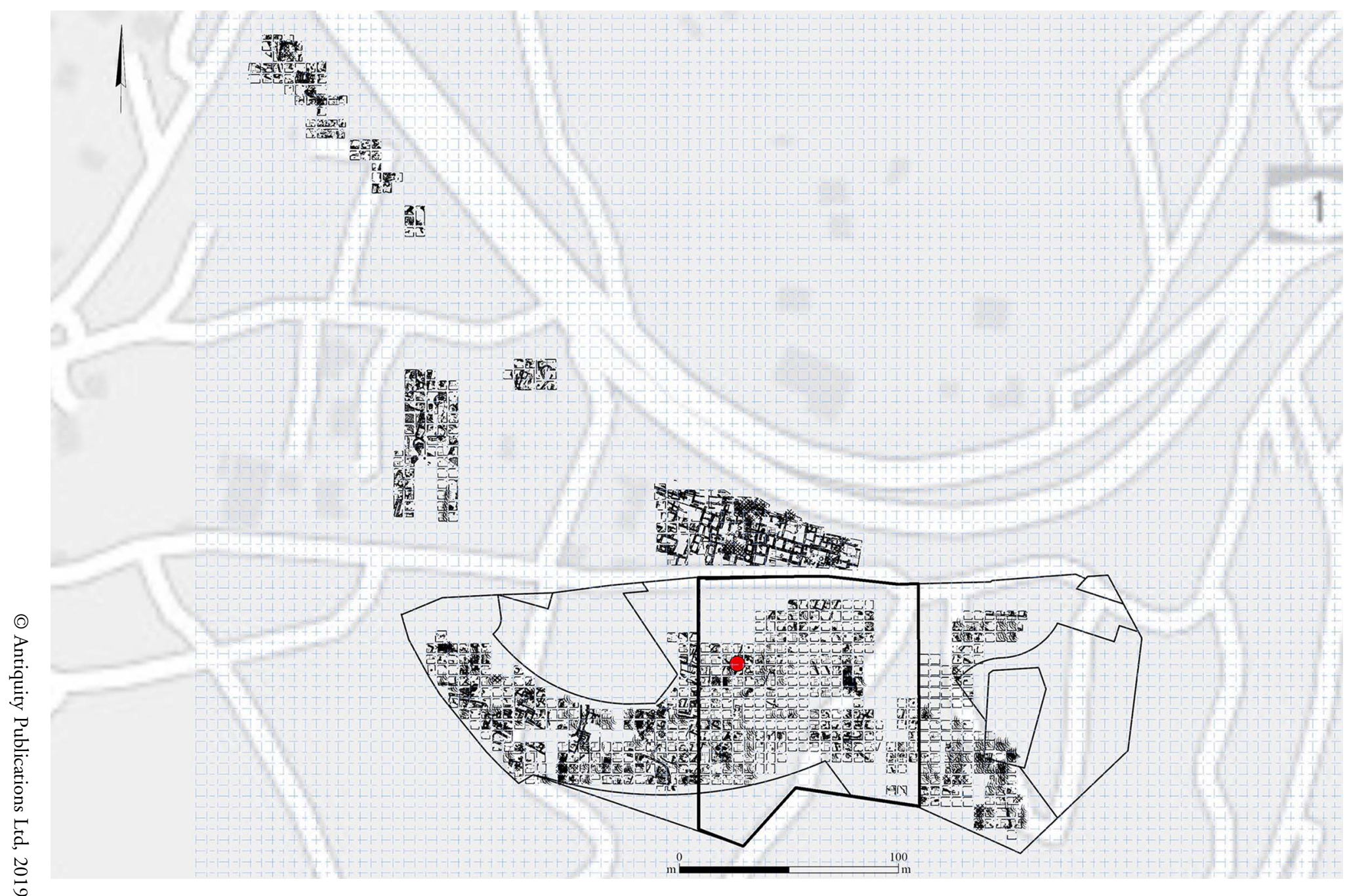

Figure 4. Site plan; area B is outlined in bold black; the location of the burial is marked in red. Plan drawn by Doaa Salman, used with permission of the Israel Antiquities Authority. 


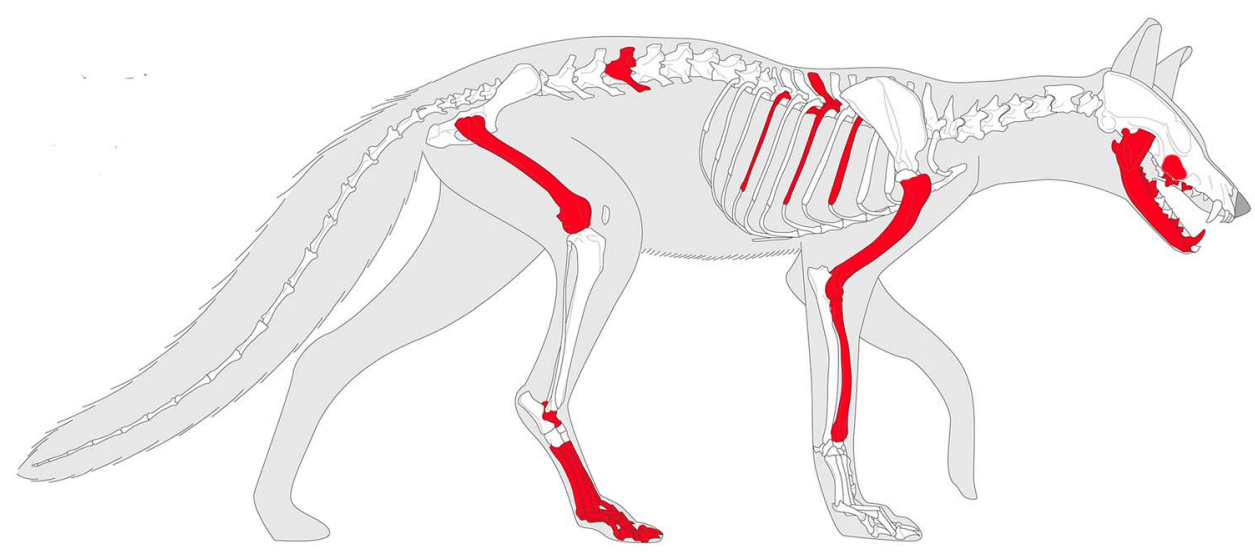

Figure 5. Skeleton of a fox with the elements found in the burial coloured red. Drawn by Michel Coutureau and Céline Bemilli and taken from ArcheoZoo.org (available at: https://bit.ly/2mLcsbV).

The location of fox bones in the grave (number of identified specimens- 43 ; minimum number of individuals-2) associates them clearly with the later double burial and is quite distinct from caprine bone fragments occurring as unstructured finds in the grave backfill. A left mandible lay on the skull of the adolescent; two right femurs and two right mandibles were positioned on the right forearm. Fox phalanges, metapodials and a fully articulated astragalus of a right leg were placed inside the funerary container of the adult under his right femur. A fox humerus and radius were also placed in the burial (Figure 5). Taphonomic processes and compaction probably account for the way that the fox remains were scattered in the burial; their original arrangement is unclear. Other finds associated with the interment include beads, shells, worked stone and a stone bracelet.

Human burials with animals dating to the transition from hunting and gathering to farming are particularly important in understanding shifting relations between humans and animals at this time (Horwitz \& Goring-Morris 2004; Vigne et al. 2004; Grosman et al. 2008; Maher et al. 2011; Meier et al. 2017). The move to permanent settlements had a dramatic effect on the immediate environment. Prolonged occupation of sites created increasing amounts of refuse and anthropogenic ecologies, which in turn attracted animals, including small carnivores such as foxes. A commensal relationship formed between these animals and humans (Zeder 2012), augmenting the role of foxes in Neolithic culture and society (Peters \& Schmidt 2004; Yeshurun et al. 2009).

(C) Antiquity Publications Ltd, 2019 
Burials with small carnivores attest to their ecologically driven increased visibility; more implicitly, they demonstrate symbolism responding to shifts in proximate animal communities. Symbolic incorporation of elements of the animal world in ritual contexts is typical of animistic, not theistic, religions (Rappaport 1979; Bird-David 1999; Russell 2011).

This liminal phenomenon of an agricultural society retaining hunter-gatherer ritual practices, and perhaps ideologies, is clearly revealed in human burials with animals. Retention of these practices supports a mosaic process of Neolithisation, in which symbolism continues to render the natural world surrounding agricultural societies as intelligible and meaningful.

\section{Acknowledgements}

The authors wish to thank the Israel Antiquities Authority for permitting publication of data from the Motza excavation. We are grateful for the ERC Starting Grant 802752 (awarded to N. Marom). We also wish to thank Aya Marck, Adva Peretz and Doaa Salman for graphic editing and designs.

\section{References}

BIRD-DAVID, N. 1999. 'Animism' revisited: personhood, environment, and relational epistemology. Current Anthropology 40: S67-91. https://doi.org/10.1086/200061

Davis, S.J. \& F.R. VALLA. 1978. Evidence for domestication of the dog 12000 years ago in the Natufian of Israel. Nature 276: 608. https://doi.org/10.1038/276608a0

Goring-Morris, A.N. 2005. Life, death and the emergence of differential status in the Near Eastern Neolithic: evidence from Kfar HaHoresh, Lower Galilee, Israel, in J. Clark (ed.) Archaeological perspectives on the transmission and transformation of culture in the Eastern Mediterranean: 89-105. Oxford: Council for British Research in the Levant \& Oxbow.

Goring-Morris, A.N. \& A. Belfer-Cohen. 2013. Different strokes for different folks: Near Eastern Neolithic mortuary practices in perspective, in I. Hodder (ed.) Religion at work in a Neolithic society: vital matters: 35-57. Cambridge: Cambridge University Press. https://doi.org/10.1017/CBO9781107239043. 004

Grosman, L., N.D. Munro \& A. Belfer-Cohen. 2008. A 12 000-year-old Shaman burial from the southern Levant (Israel). Proceedings of the National Academy of Sciences of the USA 105: 17665-69. https://doi.org/10.1073/pnas.0806030105

Horwitz, L.K. \& N. Goring-Morris. 2004. Animals and ritual during the Levantine PPNB: a case study from the site of Kfar Hahoresh, Israel. Anthropozoologica 39: 165-78.

Khalaily, H. et al. 2007. Excavations at Motza in the Judean Hills and the Early Pre-Pottery Neolithic B in the southern Levant. Paleorient 33 (2): 5-37. https://doi.org/10.3406/paleo.2007.5218

Le Mort, F., J.D. Vigne, S.J. Davis, J. Guilaine \& A. Le Brun. 2008. Man-animal relationships in the Pre-Pottery burials at Shillourokambos and Khirokitia (Cyprus, $8^{\text {th }}$ and $7^{\text {th }}$ millennia cal BC). MOM Éditions 49: 219-41.

Maher, L.A., J.T. Stock, S. Finney, J.J. Heywood, P.T. Miracle \& E.B. Banning. 2011. A unique human-fox burial from a pre-Natufian cemetery in the Levant (Jordan). PLoS ONE 6: e15815. https://doi.org/10.1371/journal.pone.0015815

Meier, J.S., A.N. Goring-Morris \& N.D. Munro. 2017. Aurochs bone deposits at Kfar HaHoresh and the southern Levant across the agricultural transition. Antiquity 91: 146983. https://doi.org/10.15184/aqy.2017.179

Peters, J. \& K. Schmidt. 2004. Animals in the symbolic world of Pre-Pottery Neolithic Göbekli Tepe, south-eastern Turkey: a preliminary assessment. Anthropozoologica 39: 179-218.

RAPPAPORT, R.A. 1979. Ecology, meaning, and religion. Richmond (CA): North Atlantic.

Russell, N. 2011. Social zooarchaeology: humans and animals in prehistory. Cambridge: Cambridge University Press. https://doi.org/10.1017/CBO9781139019712

Tchernov, E. \& F.F. Valla. 1997. Two new dogs, and other Natufian dogs, from the southern 
Levant. Journal of Archaeological Science 24: 6595. https://doi.org/10.1006/jasc. 1995.0096 Vigne, J.D., J. Guilaine, K. Debue, L. Haye \&

P. GÉRARD. 2004. Early taming of the cat in Cyprus. Science 304: 259.

https://doi.org/10.1126/science.1095335

Yeshurun, R., G. Bar-Oz \&

M. Weinstein-Evron. 2009. The role of foxes in the Natufian economy: a view from Mount Carmel, Israel. Before Farming 2009: 1-15.

https://doi.org/10.3828/bfarm.2009.1.3

Zeder, M.A. 2012. The domestication of animals. Journal of Anthropological Research 68: 161-90.

https://doi.org/10.3998/jar.0521004.0068.201

Received: 17 January 2019; Revised: 10 June 2019; Accepted: 11 June 2019

(C) Antiquity Publications Ltd, 2019 